\title{
Child Abuse and Its Manifestation
}

\author{
UNILYN E. SOLON \\ uesolon@universityofbohol.edu.ph \\ https://orcid.org/0000-0002-3791-4063
}

\section{ABSTRACT}

Child abuse is damaging to a person's psyche. Children experiencing trauma may respond to it differently. Thus, symptoms vary from physical, mental, emotional, social, behavioral, and psychological reactions. This study intends to ascertain child abuse and its manifestation among the children of the Arms of Love Children's Home, Cortes, Bohol, Philippines. It utilized a quantitative research design with the aid of a self-constructed questionnaire to gather the perceived symptoms of trauma among the sexually abused, physically abused, neglected, abandoned, and surrendered children regarding their physical, mental, emotional and interpersonal conditions, and the degree of variance among these symptoms. Results revealed that symptoms of trauma were differently manifested by the abused children in the form of physical, mental, emotional, and interpersonal conditions. On the physical conditions, the headache was mostly evident. Emotional responses to trauma were in the form of an eating problem, having guilt feelings, confusion, and hyper vigilance. Moreover, this study highlighted sexual and physical abuse as higher degree types of child abuse. However, other forms - neglected, surrendered, abandoned were not taken for granted for these are also detrimental to children's life.

Keywords: sociology, child abuse, trauma, quantitative design, Philippines 


\section{INTRODUCTION}

A child according to the United Nations Convention on the Rights of the Child is any person who is below 18 years old and under the legal control and responsibilities of parents or guardian (UNICEF, 1998). The parents with the assistance of the state shall provide a wholesome family life that will give the child love, care, and understanding, guidance and counseling, moral and security. A child needs to be loved, protected and nurtured to survive, grow, and develop normally (Council of the Welfare of the Children, 2004). In this connection, Republic Act 7610 calls for the provision of special protection to children from all forms of abuse, neglect, cruelty, exploitation, discrimination and other conditions detrimental to their development (Commission on Human Rights, 1994).

In response to this, the Provincial Ordinance No. 2000-30, otherwise known as Bohol Children's Code (Tirol, 2000) was created to ensure the protection of children against all forms of abuse, promoting their welfare, and enabling them to develop their potentials for nation-building. However, despite the existence of this law and ordinance, in 2009, the Department of Social Welfare and Development (DSWD) reported more than 400 victims of child abuse in the Province of Bohol. This number consisted of children who were physically abused, sexually abused in different forms, orphaned, abandoned, neglected, emotionally disturbed, with a disability, and victim of trafficking. This scenario is an indication that the province of Bohol is not free from different forms of child abuse. It is an important matter of concern.

This study was initiated to take part in positively responding to the needs and concerns of abused children. It is a humanitarian endeavor to advocate in protecting and uplifting the lives of these children. Hence, a study of child abuse and its manifestation was conducted to formulate a plan based on proposed recommendations. Further, it can facilitate in dealing with the abused children, meet their needs and concerns, uplift their lives, enhance their potentials, and help them properly adjust and function as individuals in the society.

In trauma, the traumatic events overpower the natural systems of care that provide human beings the sense of control, connections, and meaning. It is the affliction of the powerless (Herman, 1997). This powerlessness may result in helplessness that can lead to excessive clinginess, excessive anxiety, aggression, and dissociation (Baley, Moran and Pederson, 2007). Ford (2005) also added that abused children (as powerless) need to focus on survival through avoiding, being over-reliant 
to caregivers, and becoming hyper-vigilant. These can even become automatic responses than conscious (Ford and Cloitre, 2009). In this sense, the potentiality of an abusive atmosphere experienced by children is not far from reality. Children as powerless are overwhelmed by this traumatic force. Being powerless has a serious consideration that children are passive, dependent, and vulnerable. This finding is incorporated into their salient features as mindless, ignorant, and innocent (Ong, 2000). These weak characteristics likely expose them to abuses and therefore need protection. It is the role of the family to mold them into socially responsible adults by providing them with the basic needs, instilling discipline, and protecting them from harm and undesirable influences. It is pleasurable to know that there are many families taking responsibility for their children. They adopt friendlier parenting, keep constant contact and attachment to them, and help create a better future for them. Unfortunately, there are quite several families running away from this responsibility.

Trauma involves exposure to life-threatening situations like childhood, physical, emotional, or sexual abuse (De Prince, 2002). It is damaging to a person's psyche. It has a profound impact on the physical, mental, and behavioral functioning of children. When children, for example, experience disrupted attachment through abuse, they are unable to regulate themselves, modulate intense feelings, and rely on safe caregiving relationships (Van der Kolk, 2005). Therefore, all forms of child maltreatment put the victim's health, survival, and development at risk (Norman, Byambaa, De, Butchart, Scott, \& Vos, 2012).

When in danger, traumatized children elicit different reactions or responses to traumatic events. This may vary from physical (e.g., sleep problems, bodily symptoms with no medical basis), emotional (e.g., irrational fears, anger and outburst of thoughts and feelings), behavioral (e.g., regressive behaviors such as suck thumb or wet bed), social (e.g., withdrawal or excessive clinging) and psychological (e.g., depression, flatness, anxiety) reactions. Physical reactions are somatic complaints (e.g., headache, stomach ache) that may be acted out in response to unexpressed intense feelings (Ford \& Cloitre, 2009). Moreover, negative attributions of self and others may aggravate hypervigilance and faulty processing of information (Van der Kolk, 2005). Avoiding trauma reminders and re-experiencing it are also signs of an active struggle of the body and mind to cope with the trauma (Carlson, 2004). Williams' (2005) study on one hundred twenty-nine women with previously documented histories of sexual victimization in childhood revealed that women failed to 
remember the abuse that was reported 17 years earlier. Hence, having no memory of the said experience does not mean that it did not happen.

Psychological trauma can keep children from acquiring established intellectual, emotional, physiological, and behavioral patterns regardless of the phase of development. Consequently, they will become confused, disoriented, and terrified. These can undermine their developmental capacities. Study of Bak, (2005) suggested that exposure to early trauma predisposes persons to suffer from more emotional distress associated with psychotic experiences. They have less perceived control over these experiences as compared to those without experience. In the context of neurodevelopment, physiological hyperarousal, and dissociation, these cases are examples of adaptive mental and physical responses. The more children are in this state, the more likely they are to have neuropsychiatric symptoms (Perry, 1996). It is not surprising that children's development may be at risk of its long-term effect, and may later in life question their own identity (Carlson, 2004). Therefore, parents and caregivers fail to perform responsibility when they are not able to recognize that these children need help.

The forerunner of Psychoanalytic Social Theory, Karen Horney states that "the total childhood experience brings on a character structure" (as cited in Apruebo, 2008) that may become children's guiding tool in the process of socialization. Personality formation influences how they interpret their interaction with others in society and build a relationship. This personality is crucial in their future social relation. Erik Erikson, in his Psychosocial Theory of development, also stressed out the importance of developing a sense of trust among children. It is attained when adults can attend to their needs - warmth, care, and discipline, and provide them a safe, happy, orderly, and predictable place.

Moreover, children may develop a generalized feeling of guilt when parents make them feel incompetent. It will impede them to successfully learn to have influence over others and manipulate surroundings (as cited in Apruebo, 2008). Children must be granted certain rights such as the right to life, protection against all forms of maltreatment, and a standard of living adequate for their optimum development.

Alfred Adler (as cited in Apruebo, 2008) contended that children are born with a deep sense of inferiority. They are born weak and have inferior bodies (as mentioned in Feist \& Feist, 2008) because of their small height, physical weakness, and lack of knowledge and power compared to adults. Consequently, they are dependent on others, but when they have a feeling of unity, they can attain psychological health 
that helps them develop a sense of self. Such would help them find social progress that is more important than personal credit. The way parents interact with their children's ability may help them overcome their feelings of inferiority and achieve competency later in life. Therefore, early experiences such as being neglected, or overly pampered, or having a significant defect may have a substantial impact on how a child views his/her capacities and social interactions.

Collins, Maccoby, Steinberg, Hetherington and Bornstein (2000) made an emphasis on specific patterns of parental behavior that may affect the personality development of a child. Parents transmit messages based on observed behaviors. They may be warm and loving, or hostile and rejecting, or overprotective and possessive, or aware of their children's need for freedom or autonomy, parents influence their children's behavior by being role models for identification. The child-parent relationship later paves the way on the desire of an individual even in overcoming the feelings of anxiety. As cited in Schultz and Schultz (2009), Karen Horney (Psychoanalytic Social Theory) claimed that basic anxiety occurs when people feel isolated and helpless in a hostile world and experience various negative events such as sexual abuse, beatings, open rejection, or pervasive neglect which when encountered during childhood years affect personality development.

Thus, parents' inability to love their children and tend to dominate, neglect, overprotect, reject, or overindulge will result in the dissatisfaction of the child's needs for affection and security. Children need to experience both genuine love, and healthy discipline from a warm and loving environment for this condition allows them to grow with respect to the real self.

Children deserve a just and humane treatment - dealing with their needs and rights, protecting them from abuse or exploitation, and ensuring that their lives are not subject to excessive interference.

This study intends to ascertain child abuse and its manifestation among the children of Arms of Love Children's Home, Cortes, Bohol with the end view of putting forward recommendations. Specifically, it sought to determine the following aspects:

1. The profile of children regarding sex, age, and case classification;

2. The perceived symptoms of trauma among the sexually abused, neglected, physically abused, abandoned and surrendered children regarding their physical, mental, emotional and interpersonal conditions; and 
3. The degree of variance on the perceived symptoms of trauma among the sexually abused, neglected, physically abused, abandoned, and surrendered children around the physical, mental, emotional, and interpersonal conditions.

\section{METHODOLOGY}

This study utilized a quantitative research design to provide a statistical and numerical analysis (Creswell, 2003) on the manifestation of child abuse. A self-constructed questionnaire (English and Cebuano Version) that went through the process of correction, pretest, and approval by the Board of Director of Arms of Love Children's Home and the members of the panel during the proposal hearing was used as a data-gathering tool. It has two parts. Part I includes the Profile of the Subjects and Part II on the Perceived Symptoms of Trauma. It is a 30-item instrument using a 4point scale which asked participants to rate each item as Never, or the subject has not exhibited the conditions at all (1), Sometimes, or the subject has exhibited the conditions rarely or once in a while (2), Often or the subject has exhibited the conditions regularly or from time to time (3), and Always or the subject has exhibited the conditions at all times.

Items as the perceived symptoms of trauma were based on the literature reviewed. It was administered to the service providers of Arms of Love Children's Home, a public charity based in the United States of America and is located in Lourdes, Cortes, Bohol as the second ministry location of Arms of Love International that consisted of four homes accommodating 10-12 children with service providers per home. The service providers comprised of six house parents, four support staff, and one social worker who have been in the institution for seven to ten years. They have undergone Biblical Parenting, Love and Logic Training, weekly staff development and meeting, and case conferences which helped them become more capable of childcare within the institution. They answered the questionnaire based on the conditions and complaints they have observed on children; thus, were the participants.

There were 35 abused children in the institution - three sexually abused, 11 neglected, two physically abused, two abandoned, and 17 surrendered. Questionnaires were distributed to the service providers based on the number of children under their respective care.

Furthermore, this paper secured consent from the service providers of the Arms of Love Children's Home as well as approval from its Director. There was also a clear articulation of the mechanism of the study before 
the data gathering begins. In order to assure the quality of data gathered, it considered establishing rapport, conducting it in a comfortable space, and providing a proper debriefing. After the collection, collation and recording of sufficient data, subjecting quantitative data to statistical analysis, and safeguarding them were also taken into account. Privacy and confidentiality were observed.

Moreover, to quantitatively identify the perceived symptoms of trauma among abused children regarding physical, mental, emotional and interpersonal conditions, answers were categorized as Always, Often, Sometimes and Never with weight equivalents of 4, 3,2 and 1, respectively, using the weight mean. It is a technique used to measure the central tendency where some values are given importance over others. It is used to gauge the average value of responses to items in the questionnaire. To determine the significant degree of variance on the perceived symptoms of trauma among sexually abused, neglected, physically abused, abandoned and surrendered children, analysis of variance was used (Brase and Brase, 2012).

In the attempt to gather data on the manifestation of child abuse, this paper considered the possible risk it may bring to the participants (i.e., reexperiencing and retraumatizing the traumatic events) brought about by the conduct of the study, hence, limits its scope within the service providers' perception of children's behaviors and complaints. It also has adhered to the ethical standard set in the conduct of this study; hence, an approval from the Research Ethics Review Committee was sought. Finally, results were communicated to the participants and the Director of the Arms of Love Children's Home.

It also considered the subjective perception of the variables that this study wanted to measure. Hence, may have yielded to limit the scope of the analysis for it might be an obstacle in identifying the manifestation of child abuse.

\section{RESULTS AND DISCUSSION}

On the Profile of the Subjects. Among the 35 subjects, 20 (57.14 percent) were males, and 15 (42.86\%) were females who portrayed that the Arms of Love Children's Home has provided accommodation, care, and assistance to more male children. It also indicated that abusing children is not limited to one sex only. Children, males or females, could be victims of abuse.

Regarding their age, two $(5.71 \%)$ of the subjects were within the range of three to six years old, seven (20\%) were 7 to 10 years, five $(14.29 \%)$ 
were 11-14 years, and $21(60 \%)$ were 15 and below 18 years old. It denotes that all of them qualified as children based on the definition of child in the Convention on the Rights of the Child.

Subjects included three (8.57\%) sexually abused, eleven (31.43\%) neglected, two (5.71\%) physically abused, two (5.71\%) abandoned, and 17 (48.57\%) surrendered. The surrendered children comprised the highest number of subjects whose parents suffered from illness, incapable of giving support, and experienced parental conflict - followed by neglected and sexually abused children. Least number of the case includes physically abused and abandoned children.

On the Perceived Symptoms of Trauma. Symptoms of trauma, as presented in this paper, consider its manifestation in the form of physical, mental, emotional, and interpersonal conditions. These are aspects of the life of children that may be affected by having experienced abuse physical, sexual, neglected, abandoned, and surrendered.

Sexually abused. Findings revealed that the service providers perceived the sexually abused as having poor appetite, hyper-vigilant, confused, felt bad about himself/herself or thought that he/she is a failure or has let himself/herself and family down, felt tired or having little energy, moved or spoke so slowly, being so fidgety and restless, felt irritable, guilty, down, depressed or hopeless, and numb or not feeling emotions like he/ she used to. These are emotional conditions that were often or regularly exhibited by children, gaining a composite mean of 2.93 .

Mental responses like having repeated thoughts and vivid memories of the event, flashbacks and nightmares where one feels reliving the event, recurrent and intrusive distressing recollections of the event such as doing repetitive play on which themes of trauma are expressed, trouble in making decisions or slow thinking, becoming extremely distressed when something reminds him/her of the event, frightening dreams without recognizable content, trouble concentrating on things such as reading or watching TV, having exaggerated thoughts, and trouble falling or staying asleep were perceived to have exhibited by the sexually abused children often or regularly as these got a composite mean of 2.87 .

Interpersonal conditions were rated a composite mean of 2.40 , which indicates that children were perceived to exhibit them sometimes or once in a while.

Specifically, these include avoiding conversation about the traumatic event, avoiding people, places or activities that remind him/her of the event, avoiding to socialize, diminishing interest to participate in usual 
activities, excessive clinging having increased conflict with others, fighting due to outburst anger, and losing interest or pleasure in doing things.

Moreover, complaints on having menstrual cramps or problems with period (for females), headache, dizziness, stomach pain, back pain, pain in arms, legs, joints, knees, and hips, feeling the heart pounds, and problem on bowel movement such as constipation or diarrhea were among the physical complaints of this group of children, gaining a 2.27 composite mean which suggested that most of these conditions were sometimes exhibited. Overall findings for the manifestation of trauma among the sexually abused children revealed that they often have or regularly manifested physical, mental, emotional, and interpersonal symptoms of trauma.

Neglected. Among the four conditions indicating symptoms of trauma for neglected children as perceived by the service providers, the emotional conditions got the highest composite mean of 2.16, indicating that the symptoms were sometimes exhibited by these children. Having a poor appetite, feeling irritable, guilty, confused, numb or not feeling emotions like he/she used to, tired or having little energy, moving or speaking so slowly that other people could have noticed or the opposite, being so fidgety and restless that he/she has been moving around a lot more than usual, and feeling bad about himself/herself or that he/she is a failure or has let himself/herself and family down were among the symptoms of trauma exhibited based on the perception of their service providers. The interpersonal conditions have a composite mean of 1.93 and ranked second.

The neglected children sometimes exhibited symptoms of trauma that include diminishing interest to participate in usual activities, having increased conflict with others, fighting due to outburst anger, excessive clinging, and losing interest or pleasure in doing things. Mental conditions got a composite mean of 1.78 (ranked third) where neglected children sometimes exhibited trouble in making decisions or having slow thinking, repeated thoughts and vivid memories of the event, recurrent and intrusive distressing recollections of the event such as doing repetitive play on which themes of trauma are expressed, exaggerated thoughts, becoming extremely distressed when something reminds him/ her of the event, and trouble concentrating on things such as reading or watching TV. Symptoms of trauma in terms of physical conditions got a composite mean of 1.66, indicating these conditions were not at all exhibited by the neglected children. However, complaints on having headache and stomachache were common among them. 
These findings brought forth an overall composite mean of 1.88, suggesting that neglected children had sometimes exhibited symptoms of trauma. Although the neglected children not at all times exhibited the physical conditions, others sometimes displayed some physical symptoms of trauma. Hence, attention should be given.

Physically abused. Among the four conditions considered as the symptoms of trauma, emotional conditions ranked first with a composite mean of 3.60, described as at all times perceived by the service providers. This indicated that the emotional symptoms of trauma were apparently experienced and exhibited by the physically abused children which include fighting due to outburst anger, having increased conflict with others, excessive clinging, poor appetite or overeating, moving or speaking so slowly that other people could have noticed or the opposite, being so fidgety and restless that he/she has been moving around a lot more than usual, feeling extremely on-guard or in danger or being hyper-vigilant, feeling numb or not feeling emotions like he/she used to, confused, feeling guilty, feeling bad about himself/herself or that he/she is a failure or has let himself/herself and family down, feeling tired or having little energy, irritable, and feeling down, depressed or hopeless.

The mental conditions with a composite mean of 3.30, also described as at all times exhibited by the physically abused showed that symptoms of trauma for this group of children also encompassed the mental aspect of one's life. These mental responses to trauma were commonly exhibited by these children in terms of having exaggerated thoughts, recurrent and intrusive distressing recollections of the event such as doing repetitive play on which themes of trauma are expressed, becoming extremely distressed when something reminds him/her of the event, trouble concentrating on things such as reading or watching TV, trouble falling or staying asleep, trouble in making decisions or having slow thinking, repeated thoughts and vivid memories of the event, flashbacks, and nightmares where he/she feels reliving the event, frightening dreams without recognizable content, and foreshortened future or not expecting to have career, marriage, children and a normal life.

Third in rank was the interpersonal manifestation of trauma with a composite mean of 2.30, described as sometimes exhibited by the physically abused children. Common symptoms exhibited were having increased conflict with others, fighting due to outburst anger, excessive clinging, avoiding people, places or activities that remind him/her of the event, withdrawal, and isolation, refusing to engage in previous 
age appropriate behaviors such as self-feeding, washing, brushing teeth, self-dressing, and losing interest or pleasure in doing things.

Last in rank was the physical conditions with a composite mean of 2.20, also described as sometimes exhibited by these children. Among the symptoms perceived were based on children's complaints. These include experiencing stomach pain, headache, menstrual cramps or other problems with the period (for females), pain in the arms, legs, and joints (knees, hips, etc.), chest pain, feeling the heart pounds, shortness of breath, and constipation or loose bowel or diarrhea. These findings revealed that for physically abused children, symptoms of trauma were manifested in terms of the four conditions. Its overall composite mean of 2.85 showed that these symptoms were often exhibited by the physically abused children as perceived by their service providers. This may vary in frequency as some conditions were exhibited at all times and others were sometimes exhibited, nevertheless, regardless of its frequency, this indicated that trauma for the physically abused was manifested physically, emotionally, mentally and interpersonally.

Abandoned. Children in this group were also perceived to have exhibited the symptoms of trauma, particularly on the mental and emotional conditions which ranked first. They both have the composite mean of 2.10 , indicating that symptoms were sometimes exhibited by the abandoned children. Among the mental symptoms of trauma manifested were having trouble in making decisions or slow thinking, trouble concentrating on things such as reading or watching TV, trouble falling or staying asleep, becoming extremely distressed when something reminds them of the event, and exaggerated thoughts.

Emotional symptoms of trauma include feeling guilty, feeling confused, feeling numb or not feeling emotions like they used to, having poor appetite or overeating, feeling bad about oneself that he/she is a failure or has let himself/herself and family down, feeling tired or having little energy, moving or speaking so slowly that other people could have noticed or the opposite, so fidgeting and restless that he/she has been moving around a lot more than usual. Interpersonal conditions were also exhibited sometimes as it got a composite mean of 1.80. Fighting due to outburst anger, having increased conflict with others, refusing to engage in previous age-appropriate behaviors such as self-feeding, washing, brushing teeth, self-dressing, and diminishing interest to participate in usual activities were among the interpersonal symptoms of trauma commonly exhibited by the abandoned children. 
However, while the physical conditions were rated a composite mean of 1.25 which means that this group of children did not exhibit the overall conditions at all, headache among other symptoms appeared to have sometimes exhibited by these children. It may suggest that the manifestation of trauma was evident among abandoned children, mostly on the emotional, mental, and interpersonal conditions. However, although the physical symptoms were not well manifested, this does not mean that the conditions be taken for granted. This results stressed out that the overall composite mean of 1.81 means that abandoned children sometimes exhibited the symptoms of trauma differently.

Surrendered. Emotional, mental, and interpersonal conditions were rated a composite mean of 2.30, 2.01 and 1.89, respectively, described as symptoms of trauma sometimes exhibited by the surrendered children. Among these emotional conditions include feeling confused, feeling irritable, having poor appetite or overeating, feeling tired or having little energy, moving or speaking so slowly that other people could have noticed or the opposite, so fidgeting and restless that he/she has been moving around a lot more than usual, feeling bad about himself/herself or that he/ she is a failure or has let himself/herself and family down, feeling numb or not feeling emotions like he/she used to, and feeling guilty. This group of children also exhibited symptoms of trauma in terms of their mental conditions. These include having trouble in making decisions or slow thinking, trouble concentrating on things such as reading or watching TV, repeated thoughts and vivid memories of the event, recurrent and intrusive distressing recollections of the event such as doing repetitive play on which themes of trauma are expressed, becoming extremely distressed when something reminds him/her of the event and having exaggerated thoughts.

The interpersonal conditions were manifested in having a diminishing interest to participate in usual activities, having increased conflict with others, withdrawal and isolation, losing interest or pleasure in doing things, refusing to engage in previous age-appropriate behaviors such as selffeeding, washing, brushing teeth, self-dressing, and excessive clinging. The physical conditions got a composite mean of 1.62, described as symptoms that were not at all exhibited by the surrendered children. However, this finding did not discount the fact that some symptoms were the common complaints of children. These include having a headache, dizziness, stomach pain, and constipation, loose bowel or diarrhea. The Overall composite mean of 1.97 indicated that surrendered children also sometimes exhibited symptoms of trauma in different conditions. 
Results showed that symptoms of trauma were manifested in terms of physical, mental, emotional, and interpersonal conditions differently by the children of the Arms of Love Children's Home as perceived by their service providers. This coincides with literature pointing out that people have different reactions to traumatic events. Typical reactions or responses of traumatized children may vary from physical, emotional, behavioral, social, and psychological. Among the physical conditions, the headache was mostly evident along with with with menstrual cramps or problem with the period (for females), stomach pain, chest pain, back pain, pain in arms, legs, joints, etc., shortness of breath and feeling the heart pounds.

For Ford and Cloitre, (2009), these physical reactions can be considered as somatic complaints that were acted out in response to unexpressed intense feelings. Furthermore, findings also unearth that most children have trouble in making decisions, recurrent and intrusive distressing recollections of the event such as doing repetitive play on which themes of trauma are expressed, having exaggerated thoughts, and becoming extremely distressed when something reminds them of the event. These mental responses to trauma by the abused children substantiated Herman's (1997) contention that traumatic memories are inscribed in the form of vivid sensations and images because they lack verbal narrative and context.

Hence, children who are exposed to trauma relive the experience in thoughts, dreams, and actions such that repetitive play on themes of trauma is apparent. When children come across chaotic situations like abuses, they would have difficulty developing a clear sense of values that may result in having no clear-cut decisions throughout life. As Alfred Adler (as cited in Apruebo, 2007) postulated, the way adults particularly parents interact with their children may help them surmount feelings of inferiority and achieve competency later in life. This may be one of the contributing factors of having a good state of mind.

However, when parents fail to provide children with this kind of atmosphere, this may lead to depreciate mental ability. This finding also connects with Van der Kolk (2005) who stressed out that faulty information processing may be brought about by having negative attributions of self and others exacerbated by the abuse. Nevertheless, it is also good to take into account that among the symptoms exhibited, having a foreshortened future was least displayed. Consistent with the result on symptoms of trauma in terms of mental conditions, emotional conditions were also highlighted as all groups of abused children displayed the symptoms at all times, often and sometimes. 
Eating problem, feeling guilty, confused, and extremely on guard (hypervigilant) were common among all abused children. This supported the study of Bak, Krabbendam, Janssen, De Graaf, Vollebergh and Van Os (2005), which stressed out that exposure to early trauma predisposes persons to suffer from more emotional distress. As pointed out by Ford (2005) and Ford and Cloitre, (2009) avoiding, being over-reliant to caregivers and becoming hyper-vigilant become automatic responses to trauma than conscious for they can be a form of survival. As postulated by Erik Erikson in his Psychosocial Theory of development, developing a sense of basic trust among children is important such that when they are provided with unsafe place, they may feel incompetent and develop a generalized feeling of guilt that will impede them to successfully learn to have influence over others and manipulate surroundings (Apruebo, 2008).

On the other hand, findings of this study also revealed that among the emotional symptoms of trauma, feeling down or hopeless was found the least displayed symptom. This showed consistency with foreshortened future as least exhibited in terms of the mental responses to trauma. As a conjecture, despite the traumatic events the children have experienced, they still look forward to having a better future, a good sign of being hopeful.

As regards to the interpersonal conditions of children, all groups of abused children manifested symptoms of trauma. The common responses were avoiding conversation about the traumatic event, people, places or activities that remind them about it, had a diminishing interest to participate in usual activities, had increased conflict with others, and fought due to anger. The occurrence of these responses attested Karen Horney's (as cited in Schultz and Schultz, 2009) claim that people feel isolated and helpless in a hostile world where they have experienced various maltreatment such as sexual abuse, beatings, rejection, or pervasive neglect.

On the Analysis of Variance on the Perceived Symptoms of Trauma. To ascertain whether there is a significant degree of variance on the perceived symptoms of trauma among sexually abused, neglected, physically abused, abandoned and surrendered children in Arms of Love Children's Home, it was subject to analysis of variance. The computed $F$ was 0.047 and was found to be very much lower than the critical value of 5.74 at 30 by $4 \mathrm{df}$ and at .05 level of significance. This indicated that there was no significant degree of variance among the responses on child abuse and its manifestation which implied that all groups of abused children had exhibited symptoms 
of trauma regarding the physical, mental and interpersonal conditions as perceived by their service providers. Therefore, regardless of the type of abuse they have experienced, these children have exhibited behaviors that manifested symptoms of trauma.

\section{CONCLUSIONS}

Sexually abused, neglected, physically abused, abandoned, and surrendered children were found out to have exhibited symptoms of trauma differently as perceived by the service providers of Arms of Love Children's Home. It is an indication that the reactions or responses of children toward the circumstances they have experienced differed as well. These symptoms in the forms of physical, mental, emotional, and interpersonal were also exhibited in different frequency - always, often, sometimes and never. However, regardless of the number of times they had displayed these symptoms, the experience is detrimental to their development and future.

Moreover, findings revealed that children less likely manifested the physical symptoms of trauma as compared to both mental and emotional symptoms. Physical complaints were less likely displayed. It may signify that physical pains were not as painful as mental and emotional pains. Both the mental and emotional aspects strongly influence each other. Emotion may tell or express how the mind is acting and reacting to situations, and the mind may interpret it as favorable or unfavorable. Nevertheless, as mental tensions influence emotional disposition, it may, in turn, deliver physical expression.

Sexual and physical abuses were well-thought-out as higher degree types of child abuse taking into consideration that the sexually and physically abused children similarly exhibited the symptoms of trauma (physical, mental, emotional and interpersonal conditions) as often or from time to time as compared to other types of abuses. However, other forms of abuse such as neglect, surrender, abandon are not taken for granted for they are as well harmful to the children's life.

Finally, this study recognizes its limitation as regards to its scope and the number of respondents. It is therefore recommended for a further study that does not only limit to a single institution for children. To widen its scope, a mixed method is also highly suggested. 


\section{REFERENCES CITED}

Apruebo, R. (2007). Personality Psychology. Manila: Educational Publishing House.

Apruebo, R. (2008). Personality Psychology. Manila: Educational Publishing House.

Bak, M., Krabbendam, L., Janssen, I., De Graaf, R., Vollebergh, W., \& Van Os, J.(2005).

Early trauma may increase the risk for psychotic experiences by impacting on emotional response and perception of control. Acta Psychiatrica Scandinavica, 112(5), 360-366. Retrieved from https://bit.ly/2m4XL3e, (accessed last 8 June 2018)

Baley, H.N., Moran G., \& Pederson, D.R. (2007). Childhood maltreatment, complex trauma symptoms, and unresolved attachment in an-at-risk sample of adolescent mothers. Attachment and Human Development 9, 139-161. Retrieved from https://bit.ly/2IWVIOu, (accessed last 8 June 2018)

Brase, C.H., \& Brase, C. P. (2012). Basic Statistics. Cengage Learning Asia Pte Ltd.

Carlson, E.B. (2004). Effects of traumatic experiences: A National Center for PTSD factsheet. National Center for Post - Traumatic Stress

Disorder. Retrieved from https://bit.ly/2zzcxCb, (accessed last 3 June 2018).

Collins, W. A., Maccoby, E. E., Steinberg, L., Hetherington, E. M., \& Bornstein, M. H. (2000). Contemporary research on parenting: The case for nature and nurture. American psychologist, 55(2), 218. Retrieved from https://bit.ly/2m3OcBB, (accessed last 3 March 2018).

Creswell, J.W. (2003). Research Design: Qualitative, Quantitative and Mixed Methods Approaches ( $2^{\text {nd }}$ Ed). United States of America: Sage Publications, Inc. Retrieved from https://bit.ly/2kA0BwL, (accessed last 1 March 2018) 
De Prince, A.P. (2000). The harm of trauma: Pathological fear, shattered assumptions or betrayal?(n.p.)

Feist J., \& Feist G. (2008). Theories of Personality (2 ${ }^{\text {nd }}$ Ed.). United States of America: McGraw Hill.

Ford, J.D. (2005). Treatment implications of altered effect regulation and information processing following child maltreatment. Psychiatric Annals 35: 410-419. Retrieved from https://bit.ly/2k9Ejlm, (accessed last 1 March 2018)

Ford, J.D. \& Cloitre, M. (2009). Best practices in psychotherapy for children and adolescents. New York: Guildford Press.

Herman, J.L. (1997). Trauma and Recovery: The aftermath of violence from domestic abuse to political terror. New York: Basic Books.

Norman, Byambaa, De, R., Butchart, A., Scott, J., \& Vos, T. (2012). The Long-Term Health Consequences of Child Physical Abuse, Emotional Abuse, and Neglect: A Systematic Review and Meta-Analysis.

Retrieved from https://bit.ly/2k2wzBq, (accessed last 1 March 2018)

Ong, M.G. (2000). The role of the family in the Philippine Society and in the protection of Children's Rights at the Philippine Child Development Resource Center. Amity Foundation.

Perry, B. (1996). Childhood trauma and neurobiology of adaptation and use-dependent development of the brain: How states becomes traits. Infant Health Journal.

Republic of the Philippines, Council for the Welfare of Children (2004). Primer on Child Abuse, Protect the Rights of the Child (n.p.).

Schultz, D. \& Schultz, S.E. (2009). Theories of Personality (9th ed.). United States of America: Wadsworth Cengage Learning.

Tirol, G.O. (2000). Bohol Children's Code Provincial Ordinance. (n.p.). 
UNICEF (1998). Implementation Handbook for the Convention on the Rights of the Child (1 ${ }^{\text {st }}$ ed.). UNICEF House. Retrieved from https:// uni.cf/209sNnG, (accessed last 10 June 2018)

Van der, K. (2005). Developmental trauma disorder: Toward a rational diagnosis for children with complex trauma histories. Psychiatric Annals 35: 401-408.

Williams, L.M. (1994). Recall of childhood trauma: A Prospective Study of women's memories of child sexual abuse. Journal of Consulting and Clinical Psychology, Vol 62 (6): 1167-1176. 